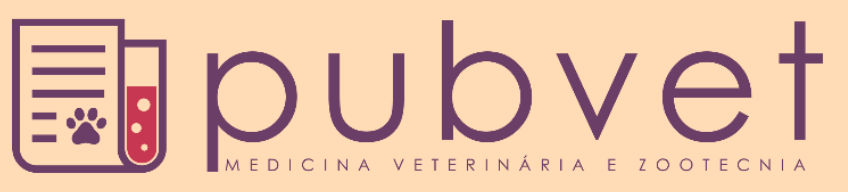

https://doi.org/10.31533/pubvet.v15n06a842.1-3

\title{
Achados citológicos em neoplasia mamária em porquinho da índia (Cavia porcellus) macho: Relato de caso
}

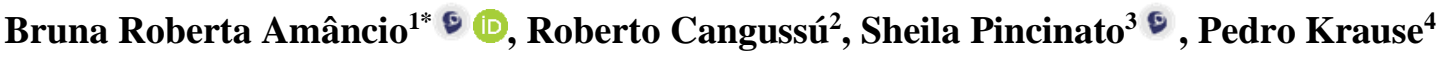 \\ ${ }^{I}$ Médica Veterinária, Mestranda em Produção Animal Sustentável pelo Instituto de Zootecnia APTA/Sertãozinho, Brasil \\ ${ }^{2}$ Graduando do $10^{\circ}$ Período de Medicina Veterinária, Faculdade Anhanguera Educacional-FAC III Unidade Taquaral, Brasil \\ ${ }^{3}$ Médica Veterinária, Faculdade Anhanguera Educacional-FAC III unidade Taquaral, Brasil \\ ${ }^{42}$ Patologista Clínico Veterinário. Profissional Autônomo, Brasil \\ *Autor para correspondência, E-mail: bruna_roberta11@hotmail.com
}

Resumo. Uma das técnicas de pesquisa de neoplasias é a avaliação citológica, sendo bem estabelecida na medicina veterinária, mas dificilmente utilizada em pequenos roedores. Em porquinhos-da-índia são incomuns as neoplasias e os trabalhos descritos na literatura incluem diferentes órgãos acometidos como pele e subcutâneo, trato reprodutivo e respiratório, sistema hematopoiético e endócrino e glândula mamária. O objetivo desse artigo foi descrever os principais achados citológicos de uma neoplasia de glândula mamária em um porquinho-da-índia macho.

Palavras-chave: Glândula mamária, neoplasia, patologia, porquinho da índia

\section{Cytological findings in breast cancer in male guinea pig (Cavia porcellus): Case report}

Abstract. One of the techniques for cancer research is cytological evaluation, which is well established in veterinary medicine, but hardly used in small rodents. Neoplasms are uncommon in guinea pigs and the studies described in the literature include different affected organs such as skin and subcutaneous tissue, reproductive and respiratory tract, hematopoietic and endocrine system and mammary gland. The aim of this article was to describe the main cytological findings of a mammary gland neoplasm in a male guinea pig.

Keywords: Guinea pig, mammary gland, neoplasm, pathology

\section{Introdução}

O Cavia porcellus é um roedor muito dócil, utilizado como animal de estimação, de laboratório e ainda como especiaria culinária em sua região de origem, as montanhas andinas (Lopes et al., 2013; Spotorno et al., 2004). Sua expectativa de vida é de quatro a cinco anos (Carpenter, 2010). O tumor mais comum encontrado em cobaias é o adenoma papilar broncogênico, seguido por tumores da pele e subcutâneo (Suárez-Bonnet et al., 2010). Existem poucos relatos na literatura sobre tumor mamário em porquinho da índia (Grandi et al., 2011). Nos estudos sobre ocorrências de neoplasias no Cavia porcellus mostrou-se baixa incidência nesta espécie. Entre 1916 e 1937, onde foram examinadas 15.000 cobaias, nenhuma apresentou neoplasias (Williams, 1991). No entanto, a incidência de neoplasia nestes animais pode chegar a 30\% após os três anos de vida, e as mais encontradas são as do trato respiratório, seguidas pelas de pele e tecido subcutâneo (Wagner \& Manning, 1976). Recentemente foi diagnosticado um lipossarcoma palpebral no olho direito de um Cavia porcellus de 18 meses de idade pela primeira vez (Quinton et al., 2013).

O objetivo deste relato foi detalhar o caso que é considerado raro na medicina veterinária, apresentando os resultados de exames citopatológico e histológico, além do exame físico e anamnese. 


\section{Relato de caso}

O estudo foi realizado em um porquinho-da-índia (Cavia porcellus), macho, com idade estimada de 5 anos, peso de 1 quilo e pelagem tricolor. Foi realizado atendimento domiciliar, em julho de 2019, e a queixa principal do tutor era uma formação nodular em região inguinal de cadeia mamária esquerda de crescimento rápido. Durante o exame físico o paciente apresentava-se hígido e com os parâmetros dentro da normalidade para a espécie (Carpenter, 2010). Ao examinar o nódulo, este possuía aproximadamente $0,5 \mathrm{~cm} \times 0,3 \mathrm{~cm}$, formato ovóide, de consistência macia e não aderido a musculatura. A anamnese não mostrou nada digno de nota. Foi então realizada coleta de material do nódulo, pela técnica da citologia aspirativa por agulha fina (CAAF). O material foi fixado em duas lâminas e encaminhado para análise citológica. Durante a análise microscópica foi observada acentuada celularidade, compostas predominantemente por células cuboides a poligonais, dispostas em grupos coesos em monocamada e arranjos acinares; com núcleos redondos a ovalados, de cromatina rendilhada e múltiplos nucléolos dispersos, e citoplasma escasso, azurofílico, ocasionalmente microvacuolizado com bordos pouco distintos. Exibição de discreto grau de anisocitose e anisocariose além de raras bis e multinucleações. Presença de grupos de células alongadas de aspecto monomórfico entremeadas em material acidofílico fibrilar, além de diversos macrófagos de aspecto xantomatoso. (Figuras 1 e 2 ).

Frente a descrição citológica, o material coletado era compatível com tumor mamário misto, sugestivo de carcinoma em tumor misto. Para avaliação e buscas de áreas de metástase, o paciente foi encaminhado a Clínica Veterinária da Faculdade Anhanguera Taquaral, para a realização de ultrassonografia abdominal e um exame radiográfico de tórax, que devido ao tamanho do paciente foi possível fazer uma avaliação de todo o corpo. Em ambos os exames de imagem não foram encontradas anormalidades. Após o diagnóstico cito patológico e exames complementares optou-se pela retirada cirúrgica do nódulo. A nodulectomia foi realizada no centro cirúrgico da Clínica Veterinária da Faculdade Anhanguera Taquaral em agosto de 2019, onde foi observado o crescimento rápido do nódulo, medindo $2,8 \mathrm{~cm} \times 1,3 \mathrm{~cm} \times 1,0 \mathrm{~cm}$ (Figuras $3 \mathrm{e} \underline{4}$ ).

Todo o material foi acondicionado em formol $10 \%$ e encaminhado para avaliação histopatológica. $\mathrm{Na}$ histopatologia observou-se macroscopicamente ao corte uma formação ovóide, parda, sólida, bem delimitada, de $0,7 \times 0,5 \times 0,5 \mathrm{~cm}$. Já na microscopia foi visualizado fragmento de pele com glândula mamária apresentando proliferação neoplásica parcialmente encapsulada, parcialmente delimitada, composta por epitélio colunar a cuboide formando áreas sólidas extensas, entremeadas por pequenos túbulos e discretas projeções papilíferas, sustentadas por septos delicados de tecido conjuntivo fibroso. Exibem citoplasma eosinofílico e núcleo redondo a ovóide, com cromatina grosseira e uma com três nucléolos puntiformes a amplos evidentes. Anisocitose e anisocariose moderadas, alta razão núcleo:citoplasma, 15 figuras de mitose em dez campos de 400x, focos de infiltração capsular de células neoplásicas e ectasia ductal com acúmulo de substância proteinácea homogênea foram observados (Figuras 5 e $\underline{6}$ ).

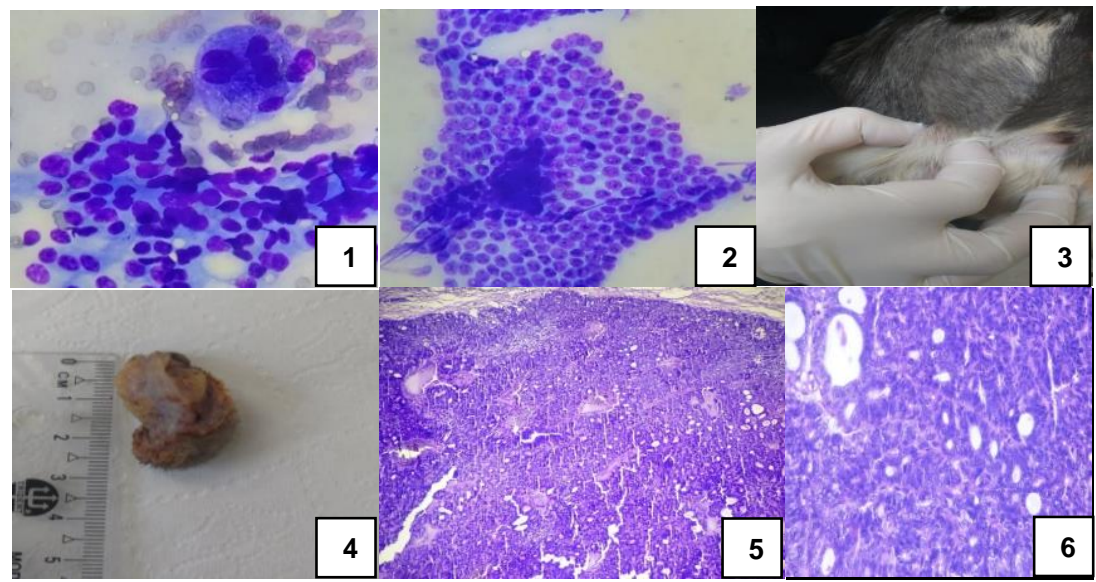

Figura 1. Aspecto microscópico citologia aspirativa por agulha fina 400x, corante panótico. Figura 2. Aspecto microscópico citologia aspirativa por agulha fina 400x, corante panótico. Figura 3. Nódulo subcutâneo. Figura 4. Aspecto macroscópico de nódulo extraído. Figura 5. Aspecto microscópico, histopatologia 100x, corante hematoxlina eosina. Figura 6. Aspecto microscópico, histopatologia 400x, corante hematoxilina eosina. 
Os achados histopatológicos eram como diagnóstico carcinoma mamário simples sólido. A tutora optou por não fazer quimioterapia, devido os riscos inerentes, então o paciente foi encaminhado para avaliação e tratamento com medicina integrativa. Nove meses após a nodulectomia o paciente segue estável e sem indícios de recidivas neoplásicas.

\section{Discussão}

A citologia aspirativa por agulha fina foi escolhida por ser uma técnica onde a coleta de material é simples de ser realizada e pode ser realizada fora do ambiente hospitalar, é pouco invasiva e o seu resultado oferece um diagnóstico preliminar de importância clínico-cirúrgica. A histopatologia, por sua vez, complementou a avaliação citopatológica, corroborando com os achados na citologia aspirativa. No presente relato, o diagnóstico através das avaliações citológicas foi extremamente importante para a definição da conduta clínico-cirúrgica e pós-cirúrgica de um paciente de pequeno porte e idade avançada para a espécie.

\section{Referências}

Carpenter, J.W., 2010. Formulário de animais exóticos. MedVet Livros, São Paulo, São Paulo, Brasil.

Grandi, F., Monteiro, L.N., Gonçalves, G.A.M., Rocha, N.S., 2011. Mammary benign neoplasm diagnosed by fine needle aspiration biopsy in a guinea pig (Cavia porcellus). Acta Veterinaria Brasilica 5, 203-206. https://doi.org/10.21708/avb.2011.5.2.2295.

Lopes, F.C., Silva, I.P., Silva, T. de M.F., Olinda, R.G., Costa, A.C., Batista, J.S., Freitas, C.I.A., 2013. Lipoma infiltrativo espontâneo em porquinho da Índia (Cavia porcellus). Revista Brasileira de Ciência Veterinária 20, 144-147. https://doi.org/10.4322/rbcv.2014.063.

Quinton, J., Ollivier, F., Dally, C., 2013. A case of well-differentiated palpebral liposarcoma in a G uinea pig (C avia porcellus). Veterinary Ophthalmology 16, 155-159. https://doi.org/10.1111/vop.12042.

Spotorno, A.E., Valladares, J.P., Marín, J.C., Zeballos, H., 2004. Molecular diversity among domestic guinea-pigs (Cavia porcellus) and their close phylogenetic relationship with the Andean wild species Cavia tschudii. Revista Chilena de Historia Natural 77, 243-250.

Suárez-Bonnet, A., Martín de Las Mulas, J., Millan, M.Y., Herráez, P., Rodríguez, F., Espinosa de los Monteros, A., 2010. Morphological and immunohistochemical characterization of spontaneous mammary gland tumors in the guinea pig (Cavia porcellus). Veterinary Pathology 47, 298-305. https://doi.org/10.1177/0300985809358426.

Wagner, J.E., Manning, P.J., 1976. The biology of the guinea pig, NY. Academic Press, Inc.

Williams, D.L., 1991. Tumors of laboratory mammals, birds and exoticanimals, in: White, R.A. (Ed.), Manual of Small Animal Oncology. United Kingdom.

Histórico do artigo:

Recebido: 4 de janeiro de 2021

Aprovado: 13 de fevereiro de 2021.
Licenciamento: Este artigo é publicado na modalidade Acesso Aberto sob a licença Creative Commons Atribuição 4.0 (CC-BY 4.0), a qual permite uso irrestrito, distribuição, reprodução em qualquer meio, desde que o autor e a fonte sejam devidamente creditados. 